\title{
Lipid Lowering Therapy Use and Achievement of Cholesterol Targets in an Australian Diabetes Clinic
}

\author{
Katerina Kiburg 1,3 \\ Glenn Ward ${ }^{1,2}$ \\ David O'Neal ${ }^{1,2}$ \\ Richard MacIsaac ${ }^{1,2}$ \\ ${ }^{1}$ Department of Endocrinology and Diabetes, St Vincents Hospital Melbourne, Fitzroy, \\ Victoria \\ ${ }^{2}$ University of Melbourne \\ ${ }^{3}$ St Vincents Institute of Medical Research, Fitzroy, Victoria
}

Correspondence to be addressed to:

Miss Katerina Kiburg

Level 4, Daly Wing, St Vincent's Melbourne

35 Victoria Parade, Fitzroy VIC 3065

t: +61392313574

email: katerina.kiburg@svha.org.au

Word count:

Abstract 57 words

Main text 1451 words

This is the author manuscript accepted for publication and has undergone full peer review but has not been through the copyediting, typesetting, pagination and proofreading process, which may lead to differences between this version and the Version of Record. Please cite this article as doi: 10.1111/imj.13691

This article is protected by copyright. All rights reserved. 


\section{Lipid Lowering Therapy Use and Achievement of Cholesterol Targets in an}

Australian Diabetes Clinic

\section{Brief abstract:}

We documented temporal changes in the use of lipid lowering medications and achievement of cholesterol targets in an Australian diabetes clinic. The number of patients using lipid lowering therapy for primary or secondary cardiovascular prevention increased from $6 \%$ to 69\% between 1993-1995 and 2014-2016 which corresponded to a decrease in LDL-C levels from 3.7 to $2.4 \mathrm{mmol} / \mathrm{L}(\mathrm{p}<0.01)$. 
Patients with diabetes are at high risk for the development of cardiovascular (CV) disease. Statins have been shown to reduce $\mathrm{CV}$ events in direct relationship to their LDL-cholesterol (LDL-C) lowering effect(2). However, there have been no long-term studies documenting the achievement of LDL-C targets and the uptake of lipid lowering medications in patients attending diabetes clinics in Australia. Our objective was to document temporal changes in LDL-C levels and the use of lipid lowering medications in patients attending diabetes clinics at an Australian university teaching hospital.

We studied patients attending diabetes clinics at St Vincent's Hospital Melbourne, Australia With ethical approval for this quality assurance project being obtained from St Vincent's Research and Governance Department Melbourne. Information was extracted from a clinic database from 1993 to 2016. The patient population had a mean age of 62.8 years $(62.8 \pm 19.11)$, of which, $75.9 \%$ had type 2 diabetes and $18.2 \%$ had a history of CV disease. We determined the percentage of patients on lipid-lowering therapy and LDL-C levels and grouped the data by number of patients results in order to ensure a minimum overall sample size was greater than 30 patients per 3 year observation period and then represented the results as a line of best fit using lowess smoothing(5). All analysis was done using STATA 14.1. 


\section{Figure 1: Uptake of Lipid Lowering Therapy and Mean LDL-C Results over Time.}

Figure 1 shows that the use of anti-lipid therapy increased from $6 \%$ to $69 \%$ of patients between the time periods 1993-1995 and 2014-2016 ( $\mathrm{p}<0.01$, students t-test). This corresponded to a decrease in LDL-C levels from $3.7 \mathrm{mmol} / \mathrm{L}$ to $2.4 \mathrm{mmol} / \mathrm{L}(\mathrm{p}<0.01)$. There was a strong negative correlation between anti-lipid therapy use and LDL-C levels $(\mathrm{r}=-0.88, \mathrm{p}<0.01)$. The publication dates of three major 'statin-trials', arbitrarily selected for illustrative purposes only, in subjects with and without diabetes are also shown on the diagram, i.e. The Scandinavian Simvastatin Survival Study (4S)(1), Primary prevention for cardiovascular disease with atorvastatin in type 2 diabetes (CARDS)(3) and the Cardiovascular benefits and diabetes risks of statin therapy in primary prevention (JUPITER)(4). In patients with and without a history of CV disease, the use of anti-lipid therapy and LDL-C levels achieved at 8 different observation periods during the study period is shown in table 1. Patients with or without a history of CV disease had a decrease in mean LDL-C from 1993-1995 to 2014-2016 of 3.55 to $2.29(\mathrm{p}<0.01)$ and 3.67 to $2.52 \mathrm{mmol} / \mathrm{L}(\mathrm{p}<0.01)$, respectively. There was a similar decrease in non-HDL-C levels from 4.66 to $3.22 \mathrm{mmol} / \mathrm{L}(\mathrm{p}<0.01)$ between 1993-1995 to 2014-2016, respectively. Generally the percentage of patients who have achieved lipid treatment targets that were current at the time the data was collected was found to have increased. For 1992-1995, 35.8\% were meeting the 1992 American Diabetes Association (ADA) target of $<3.36 \mathrm{mmol} / \mathrm{L}$, in 20042006 this rose to $46.3 \%$, reaching the target of $<2.60 \mathrm{mmol} / \mathrm{L}$ set in 2003 by the ADA. In 2013 targets were introduced by the ADA with specific reference to CVD history with $66.5 \%$ of our patients without a history of CVD meeting a target of $2.60 \mathrm{mmol} / \mathrm{L}$ during 2013-2015. However, only $29.4 \%$ with a history of CVD met the target of $<1.80 \mathrm{mmol} / \mathrm{L}(6-8)$. Similar results have been reported for the community based Australian, Fremantle Diabetes Study 1 and 2 which ran during 1993-1996 and 2009-2011 and saw a reduction in LDL-C from 3.3 to 2.3mmol/L. These studies were also able to show a similar uptake of lipid lowering therapy from $11 \%$ to $68 \%(9)$. In the years 
2010-2016 the breakdown of lipid-lowering medication was 79\% for statins, $14 \%$ for fibrates, $5 \%$ for ezetemibe and $2 \%$ for other agents. During the years $2010-2016$, the majority of patients (44\%) taking a statin were on a dosage greater than $40 \mathrm{mg}$ a day, $23 \%$ were taking a dose between $20-40 \mathrm{mg}$ a day and $33 \%$ took a dosage less than $20 \mathrm{mg}$ a day. Information regarding the type of lipid lowering therapy prescribed for patients attending our clinic was not available prior to 2010

\section{Table 1: LDL-C measurements and cardiovascular disease history}

The results of our audit suggest that there has been a substantial increase in the use of lipid lowering therapies by patients with diabetes over the last 20 years, which has resulted in a significant improvement in LDL-cholesterol levels. It should be noted that our clinic population includes patients with type 1 and type 2 diabetes. There are known limitations in the use of the Friedewald equation for the calculation of LDL-C in patients with elevated triglyceride levels(10). For this reason patients with a triglyceride level $>4.5 \mathrm{mmol} / \mathrm{L}$ were not included in our audit. Although statin therapy is recommended for the vast majority of patients with diabetes the use of statins in very young patients with type 1 diabetes may not be warranted. The above trends appear to be influenced by the publication of the results from major statin trials. A preliminary analysis of the $\mathrm{HbA} 1 \mathrm{c}$ and blood pressure data over time from our clinic found a lack of improvement compared to the significant reduction in LDL-C. In the STENO-2 study, patients in the conventional arm only experienced minor reductions in HbAlc $(0.2 \pm 0.3 \%)$, systolic blood pressure $(-3 \pm 3 \mathrm{~mm} \mathrm{Hg})$ and diastolic blood pressure $(-8 \pm 2 \mathrm{~mm} \mathrm{Hg})$ over 8 years. The STENO-2 study showed a reduction of $0.72 \pm 0.33 \mathrm{mmol} / \mathrm{L}$ in LDL-C in the conventional therapy arm (11).

The risks and benefits associated with statin use has been a recent topic for discussion both in the medical and broader community(12). A recent review has suggested that for every 10,000 patients treated with an effective statin regime for 5 years, there are 5 cases of myopathy, 50-100 of new 
onset diabetes and 5-10 of haemorrhagic strokes (13). It is estimated that for every year an individual takes a statin, the risk of a major vascular event or the need for coronary revascularisation decreases by $25 \%$ for each $\mathrm{mmol} / \mathrm{L}$ reduction in LDL-C, with absolute benefits being dependant on an individual's background CV risk profile(13). Although these rates may be lower than seen in clinical practice our clinic does not routinely systematically collect information on statin myopathy incidence.

There are a range of varied recommendations for the commencement for lipid lowering therapy and targets for LDL-C levels. These range from assessments based on an individual's risk factors to group based risk level assessment as advocated by The Canadian Cardiovascular Society(14). The Canadian Cardiovascular Society recommends the use of statins in any patients with diabetes over the age of 40 , diabetes patients with microvascular disease or type 1 patients over the age of 30 who have had had diabetes for more than 15 years(14). These guidelines recommend targeting a LDL-C level of below $2.0 \mathrm{mmol} / \mathrm{L}$. The US Preventative Services Task Force released an updated version of their 2008 recommendations regarding statin use in November 2016. They recommend the use of low to moderate dose statins in adults aged 40-75 years without a history of CV disease but with 1 or more risk factors, including diabetes, and a $10 \%$ or greater risk of experiencing a $\mathrm{CV}$ event during the next 10 years. The guidelines suggest using the Pooled Cohort Equations to calculate 10 year risk of CVD as developed by the American College of Cardiology and American Heart Association(15). The Australian College of General Practitioners bases their recommendation for the use of statins in patients with type 2 diabetes on an assessment of each individual's absolute CV risk and also recommend a LDL-C target of $<2 \mathrm{mmol} / \mathrm{L}(16)$. The National Heart Foundation of Australia and Cardiac Society of Australia and New Zealand recommend a general primary prevention target of $<2.0 \mathrm{mmol} / \mathrm{L}$ and a secondary prevention target of $<1.8 \mathrm{mmol} / \mathrm{L}(17,18)$. Our results suggest that there has been a substantial decrease in LDL-C in patients with diabetes who do not have a clinical 
history of $\mathrm{CV}$ disease. This must likely reflects the appreciation of the increase CV disease risk that a diagnosis of diabetes conveys, and the proven benefits of statins for the primary prevention of $\mathrm{CV}$ disease in diabetes(19).

The release of generic statins, and regulatory interventions aimed at reducing the cost of many medications should improve access to statin therapy for many patients with diabetes, who currently do not fulfil the Pharmaceutical Benefit Scheme indications for subsidised prescriptions. The impact of these changes on the actual uptake of statins and an expected corresponding drop in LDL-C levels await to be documented by future audits. The use of newer lipid lowering therapies, such as the PCSK9 inhibitors, although not currently used in patients with diabetes shows promise, with some early studies showing a greater mean reduction in LDL-C when treated with a PCSK9 inhibitor compared to standard treatment with statins in patients with type 2 diabetes(20,).

\section{References}

This article is protected by copyright. All rights reserved. 
1. Pederson TR, Kjekshus J, Berg K, Haghfelt T, Faergeman O, Faergeman G et al.

Randomised trial of cholesterol lowering in 4444 patients with coronary heart disease: the Scandinavian Simvastatin Survival Study (4S). Lancet. 1994;344.

2. Morris PB, Ballantyne CM, Birtcher KK, Dunn SP, Urbina EM. Review of Clinical Practice Guidelines for the Management of LDL-Related Risk. J Am Coll Cardiol. 2014;64(2):196-206.

3. Colhoun H, Betteridge D, Durrington P, Hitman G, Neil H, Linvingstone S et al. Primary prevention of cardiovascular disease with atorvastatin in type 2 diabetes in the Collaborative Atorvastatin Diabetes Study (CARDS): multicentre randomised placebo-controlled trial. Lancet. 2004;364:685-96.

4. Ridker P, Pradhan A, MacFadyen J, Libby P, Glynn R. Cardiovascular benefits and diabetes risks of statin therapy in primary prevention: an analysis from the JUPITER trial. Lancet. 2012;380(9841):565-71.

5. Cleveland SW, Devlin JS. Locally Weighted Regression: An Approach to Regression Analysis by Local Fitting. . J Am Stat Assoc 1988;83(403):596-610.

6. Garber A, Vinik A, Crespin S. Detection and Management of Lipid Disorders in Diabetic Patients. Diabetes Care. 1992;15(8):1068-74.

7. American Diabetes Association. Management of Dyslipidaemia in Adults With Diabetes. Diabetes Care. 2003;26(Supplement 1):S83-S6.

8. American Diabetes Association. Standards of Medical Care in Diabetes - 2013. Diabetes Care. 2013;36(Supplement 1):S11-S66.

9. Baba M, Davis WA, Norman PE, Davis TME.Temporal changes in the prevalence and associates of diabetes-related lower extremity amputations in patients with type 2 diabetes: the Fremantle Diabetes Study. Cardiovasc Diabetol. 2015;14(152).

10. Hirsch G, Vaid N, Blumenthal RS. The significance of measuring non-HDL-cholesterol. Prev Cardiol. 2002;5(3):156-9.

11. Gaede P, Vedel P, Larsen N, Jensen G, Parving HH, Pedersen O. Multifactorial intervention and cardiovascular disease in patients with type 2 diabetes. $\mathrm{N}$ Eng J Med. 2003;348(5):383-93.

12. Wendling P. Statin safety claims in Lancet reignite acrimony, scientific divide. Medscape [Internet]. 20168 Feb 2017. Available from: http://www.medscape.com/viewarticle/869125. 13. Collins R, Reith C, Emberson J, Armitage J, Baigent C, Blackwell L, et al. Interpretation of the evidence for the efficacy and safety of statin therapy. Lancet. 2016 Sep 8.

14. Anderson TJ, Gregoire J, Pearson GJ, Barry AR, Couture P, Dawes M, et al. 2016 Canadian Cardiovascular Society Guidelines for the Management of Dyslipidemia for the Prevention of Cardiovascular Disease in the Adult. The Canadian journal of cardiology. 2016 Nov;32(11):1263-82. PubMed PMID: 27712954.

15. US Preventive Services Task Force, Bibbins-Domingo K, Grossman DC, Curry SJ, Davidson KW, Epling JW Jr, García FA et al. Statin Use for the Primary Prevention of Cardiovascular Disease in Adults: US Preventive Services Task Force Recommendation Statement. JAMA. 2016;316(19):1997-2007.

16. Royal Australian College of General Practitioners. General practice management of type 2 diabetes. Melbourne: RACGP, 2016.

17. National Vascular Disease Prevention Alliance. Absolute cardiovascular disease management. Quick reference guide for health professionals. 2012.

18. National Heart Foundation of Australia and the Cardiac Society of Australia and New Zealand. Reducing risk in heart disease: an expert guide to clinical practice for the secondary prevention of coronary heart disease. Melbourne: National Heart Foundation of Australia, 2012. 
19. Taylor F, Huffman MD, Macedo AF, Moore THM, Burke M, Davey Smith G, et al. Statins for the primary prevention of cardiovascular disease. Cochrane Database of Sys Rev. 2013 (1). 20. Sattar N, Preiss D, Robinson JG, Djedjos CS, Elliott M, Somaratne R, et al. Lipid-lowering efficacy of the PCSK9 inhibitor evolocumab (AMG 145) in patients with type 2 diabetes: a metaanalysis of individual patient data. Lancet Diabetes Endocrinol. 2016;4(5):403-10.

\section{Legend for tables and graphs:}

Figure 1: Uptake of Lipid Lowering Therapy and Mean LDL-C Results over Time. 
The publication dates of major trials in subjects with and without diabetes are also shown.

4S Study - The Scandinavian Simvastatin Survival Study (4S). The Lancet. 1994 (1)

CARDS Study - Primary prevention of cardiovascular disease with atorvastatin in type 2 diabetes.

The Lancet. 2004(3)

JUPITER Study - Cardiovascular benefits and diabetes risks of statin therapy in primary prevention. The Lancet. 2012(4)

Table 1: LDL-C measurements and cardiovascular disease history

${ }^{1}$ Patients were classified as having a history of CV disease if they had one of the following: AMI, stroke, CABG, Angioplasty or carotid artery disease.

Note: Only the first LDL-C level available for an individual patient per time period was included in this analysis.

Figure 1: Uptake of Lipid Lowering Therapy and Mean LDL-C Results over Time.

The publication dates of major trials in subjects with and without diabetes are also shown.

This article is protected by copyright. All rights reserved. 


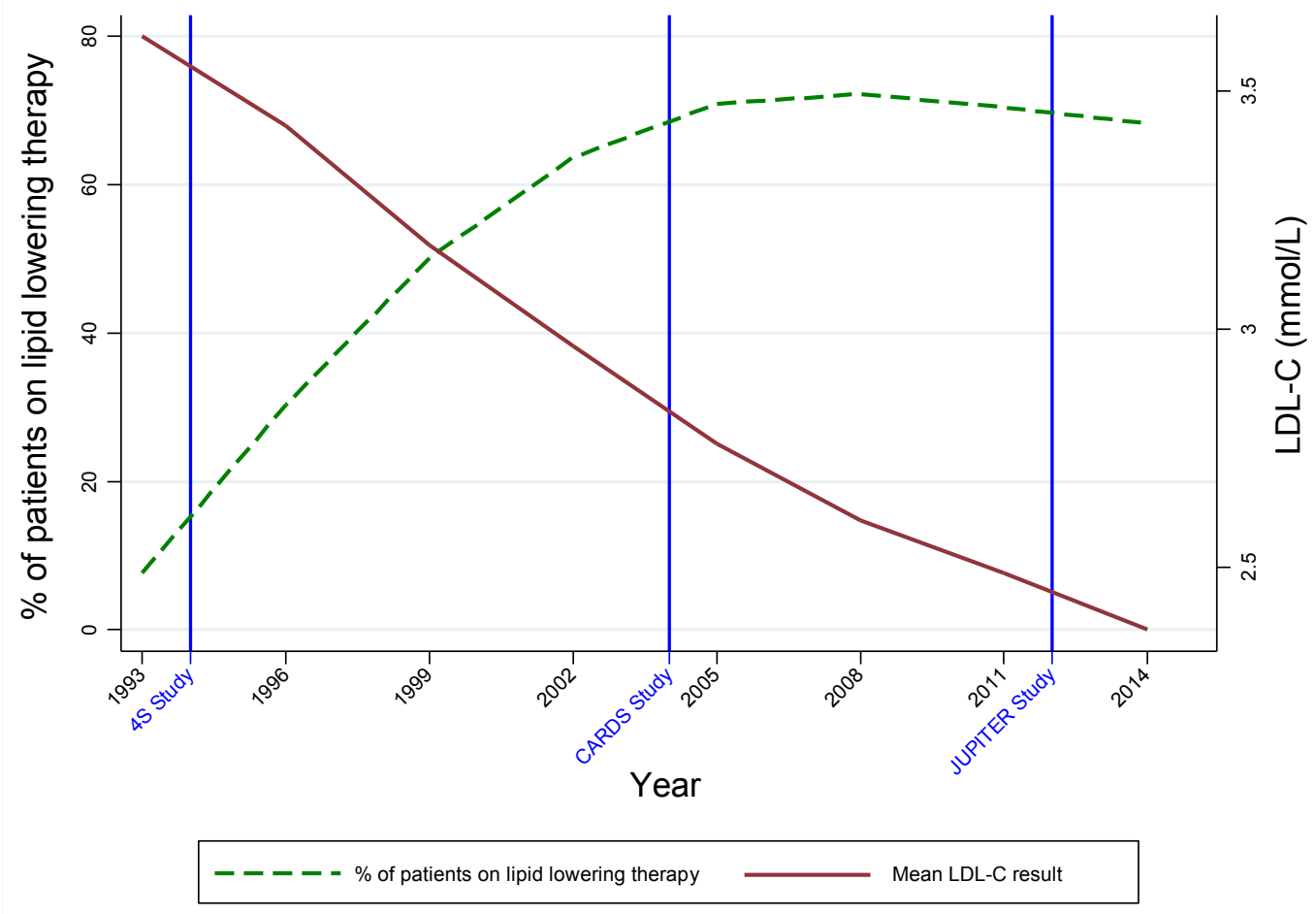

4S Study - The Scandinavian Simvastatin Survival Study (4S). The Lancet. 1994 (1)

CARDS Study - Primary prevention of cardiovascular disease with atorvastatin in type 2 diabetes. The Lancet. 2004(3)

JUPITER Study - Cardiovascular benefits and diabetes risks of statin therapy in primary prevention. The Lancet. 2012(4)

Table 1: LDL-C measurements and cardiovascular disease history 


\begin{tabular}{lccccc}
\hline & Mean LDL-C & $\mathbf{N}$ & Mean LDL-C & $\mathbf{N}$ & \\
\hline $1993-1995$ & $3.55(1.7,6.3)$ & 37 & $3.67(1.40,8.90)$ & 118 & 155 \\
$1996-1998$ & $2.85(2.46,3.24)$ & 64 & $3.18(1.17,4.44)$ & 40 & 104 \\
$1999-2001$ & $2.30(2.36,3.64)$ & 212 & $3.19(2.20,4.12)$ & 105 & 317 \\
$2002-2004$ & $2.50(1.17,3.71)$ & 378 & $2.38(1.32,4.23)$ & 174 & 552 \\
$2005-2007$ & $2.48(0.97,3.38)$ & 301 & $2.64(1.32,3.82)$ & 100 & 401 \\
$2008-2010$ & $2.14(0.98,4.4)$ & 478 & $2.43(0.99,4.13)$ & 237 & 715 \\
$2011-2013$ & $2.09(0.27,5.55)$ & 427 & $2.27(0.23,5.54)$ & 477 & 904 \\
$2014-2016$ & $2.29(0.03,6.72)$ & 831 & $2.52(0.14,6.09)$ & 192 & 1023 \\
\hline
\end{tabular}

${ }^{\dagger}$ Patients were classified as having a history of CV disease if they had one of the following: AMI, stroke, CABG, Angioplasty or carotid artery disease.

Note: Only the first LDL-C level available for an individual patient per time period was included in this analysis. 


\section{University Library}

\section{- M M N E R VA A gateway to Melbourne's research publications}

Minerva Access is the Institutional Repository of The University of Melbourne

Author/s:

Kiburg, KV;Ward, GM;O'Neal, DN;Maclsaac, RJ

Title:

Lipid-lowering therapy use and achievement of cholesterol targets in an Australian diabetes clinic

Date:

2018-02-01

Citation:

Kiburg, K. V., Ward, G. M., O'Neal, D. N. \& Maclsaac, R. J. (2018). Lipid-lowering therapy use and achievement of cholesterol targets in an Australian diabetes clinic. INTERNAL MEDICINE JOURNAL, 48 (2), pp.201-204. https://doi.org/10.1111/imj.13691.

Persistent Link:

http://hdl.handle.net/11343/283574 